\title{
A Review of Solar Still Assessment with Various PCM Materials
}

\author{
Pradeep Sen \\ M. Tech Scholar \\ M.E., Thermal Engineering \\ Truba Institute Of \\ Engineering \& Information \\ Technology \\ Bhopal, Madhya Pradesh, \\ India
}

\author{
Prof. Pankaj Badgaiyan \\ Assistant Professor \\ M.E., Thermal Engineering \\ Truba Institute Of \\ Engineering \& Information \\ Technology \\ Bhopal, Madhya Pradesh, \\ India
}

\author{
Prof. Bharat Girdhani \\ Assistant Professor \\ M.E., Thermal Engineering \\ Truba Institute Of \\ Engineering \& Information \\ Technology \\ Bhopal, Madhya Pradesh, \\ India
}

\author{
Prof. Shamir Daniel \\ Assistant Professor \\ M.E., Thermal Engineering \\ Truba Institute Of \\ Engineering \& Information \\ Technology \\ Bhopal, Madhya Pradesh, \\ India
}

\begin{abstract}
Solar distillation purifies water by transferring sun's heat to a simple device. A shallow basin with a glass shield makes up the majority of the system, which is usually referred to as a solar even now. Evaporation takes place when the pool water is heated by the sun. Humidity rises, condenses on the shield, and drips into a drip tray, leaving salts, minerals, as well as the majority of contaminants behind. The oceans, that have a high salinity, are now the only nearly inexhaustible source of water supply.Separating salts from seawater, on the other hand, necessitates a huge amount of energy, that also, when derived from fossil fuels, can be destructive to the environment. As a result, desalination of seawater must be done using environmentally friendly energy sources. PCM which are solar, are widely used to store solar radiation during the day and release it in the evening, in a wide range of solar applications.
\end{abstract}

Keywords: PCM, CFD, solar still, TSS

\section{INTRODUCTION}

The solar still has been around for several more years as a simplified and sustainable process of obtaining water. Moreover, when compared to other desalination methodologies, its main drawback is its low productivity. This problem was the subject of extensive research, with the goal of establishing reconfigured solar stills that are more productive. However, sustaining economy and easiness in building projects, maintenance, and execution is one of the primary concerns when boosting productivity.Customized solar stills, usually involving distinct condensers, heat collectables, reflectors, solar tracking system, and other components, often take up more space and are more complicated, so the higher productivity cannot justify the higher costs.
And from the other side, an innovative and simplistic reconfiguration to the traditional solar still has been tried to created, which has been dipicted to boost productivity immensely with least price hikes. As a result, using solar stills to distil sea or salt water to produce clean water is energy efficient, however the distillation speed is poor.

Enhancing the effectiveness of solar distillation is a critical task for raising clean water productivities, establishing an optimal system, and lowering investment costs. These can be accomplished by inverting different parameters using an appropriate computational formula of solar stills. Solar still modelling has been attempted employing Computational Fluid Dynamics (CFD) [1].

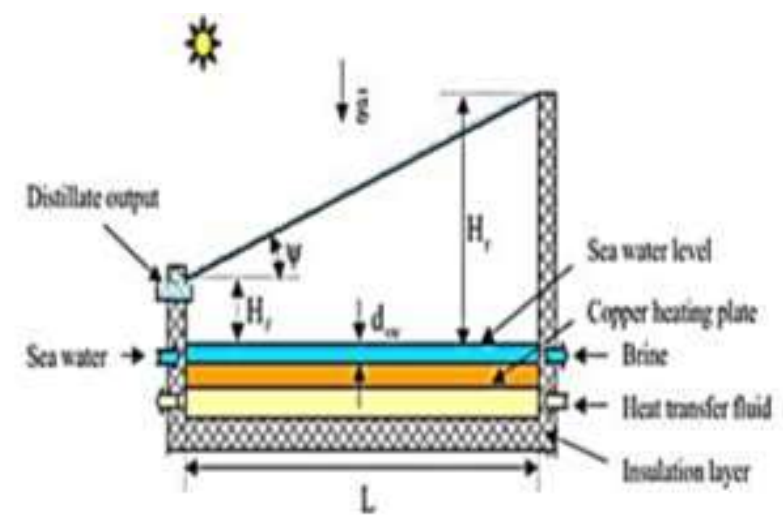

Fig. 1: Single Slope Solar Still 
1. Benifits

- $\quad$ Easy to design and install.

- Compact size

- The process gives purified water at a cheaper price in households and commercial communities without using static gadgets (blades, motors, etc.).

- It is environmentally friendly because it uses only renewables and does not damage the environment.

- Does not necessitate an operator with in-depth understanding of work, maintenance, or potential weaknesses.

2. Drawbacks

- This method necessitates huge areas of land with abundant solar radiation for assembling and work;

- This technique necessitates huge areas of land with abundant solar radiation for assembling and work;

\section{LITERATURE REVIEW}

C. Gnanavel and colleagues [2] The overall goal of this study is to boost the productivity of the solar still through using phase change material. The experimental procedure comprised of aluminium basins with phase change material often without phase change material. The testing was performed in the morning from 7 a.m. to 6 p.m., and the results were determined by calculating for either with or without PCM material. Trimethylolethane and $\mathrm{C} 18$ paraffin were used in this investigation, and the outcome of the $\mathrm{C} 18$ paraffin material provides maximum productivity. The similar values are endorsed using CFD analysis as a result of the analysis.

PratibhaKuraria et al. [3] Freshwater became a sacred source of information as a result of rapid population growth and mechanisation. As a result of both, the existable water has degraded in efficiency and is now extremely hazardous to consume. Solar distillation is a cost-effective way of cleaning salt water. Solar distillation helps eliminate soluble salts and contaminants from water by following the similar principles as the water cycle.

Farhan Lafta Rashid et al. [4] Desalination of salt water using solar systems has lengthy been a feasible solution for the manufacturing of distilled water, particularly in rural regions that endure from drinking water scarcity due to weak infrastructure, most of which are not attached to the national water supply network. ANSYSCFD was used to establish the model. The model was conducted in the transition state to verify experimentations on the performance of the solar distillation in the metropolitan area of Karbala, Iraq (latitude $32.6^{\circ} \mathrm{N}$, longitude $02^{\circ} \mathrm{E}$ ).

Swellam W. Sharshir et al. [5] Filtration of energy and water utilising solar energy has played a pivotal role in sustaining life in past few years, due to the increasing price and scarcity of safe drinking water, and it has reduced significantly the impacts of global warming gases induced by fossil fuel combustion.Heat Energy Storage Materials are used to capture the energy during the day (sunny period) and ejaculate it at night (sunset time), which is why they've always been used to improve desalination processes' effectiveness.

C. Uma Maheswari and colleagues [6] The present study is focused on the theoretical and analytical analysis of individual basin solar still in simple orientation using nhancede models of stepped and fluted PCM equipment (Phase Modification Materials). The research will also include dual slope solar stills for single basins, and the harvests will be evaluated by comparing. Pelvic slopes of 15 degrees and 20 degrees were tried to compare. When compared to various grades, an only one tilt with $20^{\circ}$ electronic instruments and PCM results in increased productivity.

M.M. Ali Saeed et al. [7] The primary goals of this study are to find the optimal variables of PCM mass, NPCM mass, water mass, and radiation from the sun in order to increase the model's productivity in the environment of Najaf: The performance of single-slope solar systems using varying masses of PCM even without nanoparticles were characterized. The thermal conductivity of paraffin wax is improved with nanoparticles. The melting point, where the most main active properties are investigated, complements the particular thermal properties of the most widespread utilised paraffin wax (PCM) and Al2O3 (nanoparticles).

M. Elashmawy and colleagues [8] This study describes the design and implementation of three various experimental tests in the town of Hail $\left(27.5^{\circ} \mathrm{N}, 41.7^{\circ} \mathrm{E}\right)$ in Saudi Arabia, which used a tubes solar still with a rectangle shaped channel, filled with a black cloth, and saturated with sample of water on the foremost testing, a Tube Solar Still with a semi-cylindrical channel without clothes in the second experiment; and the TSS of the second experiment with a parabolic concentrator solar trough in the third test group. In comparison to conventional TSS, the findings suggest that PCSTTSS has a lot of potential.

A.E. Kabeel et al. [9] This document shows how TSS with integrated deck cooling can increase the daily rate of water production. The system is comprised of a transparent solar tube that raises solar radiation as well as a black bucket that 
improves absorption of water and evaporation. TSS is made of compact materials that attain strength and durability through the use of locally sourced materials. Various pool water depths $(0.5,1,2$, and $3 \mathrm{~cm})$ were investigated in order to find the best water depth. Also, experiment with various cooling flow rates $(1,2,3$, and $1 / \mathrm{h})$ to find the best one.

\section{SOLAR STILLS Of SEVERAL TYPES}

Solar stills are separated into two categories:

A. Passive solar stills: Stills that use solar energy as the foremost heat source, including those that merge it with solar thermal energy, raise the temperature of water directly and then establish the distillation impact. This rapid development is explained by the low operating temperature and vapour pressure. [10]

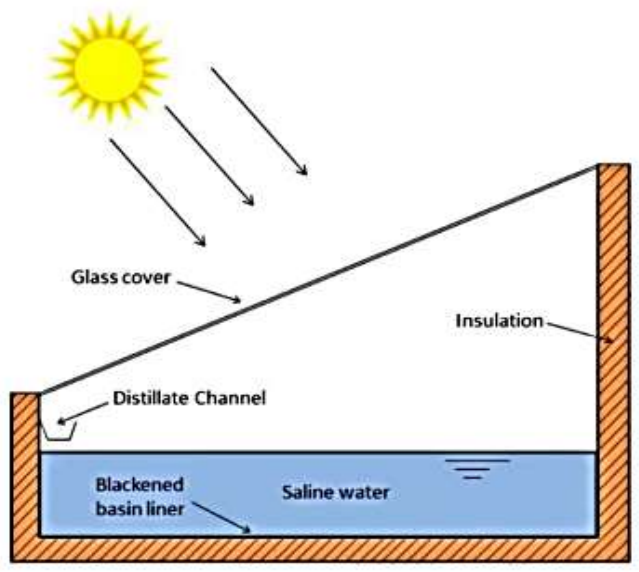

Fig. 2. Passive solar still

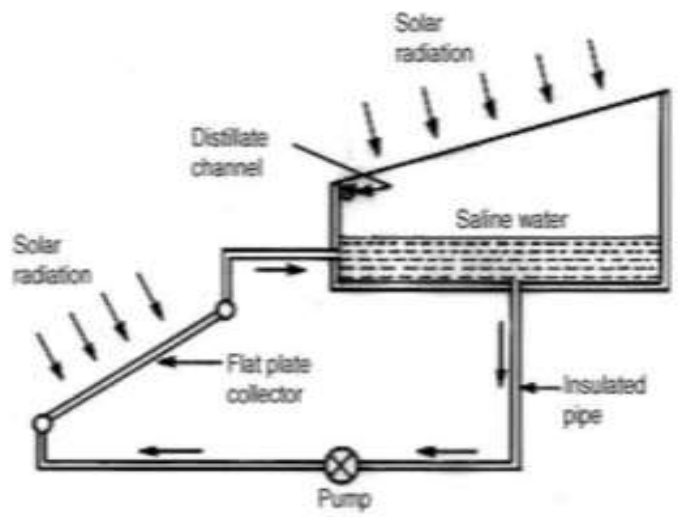

Fig. 3. Active solar still

Active solar stills: This type of additional thermal energy is coupled with passive solar for quicker vaporization, and it can be gathered from a sunlightgatherer or somewhatsurplus heat energy produced by any industrializedlocation. [10]

\section{B. THERMODYNAMIC AND THERMO ECONOMIC ANALYSIS OF} SOLAR STILL WITH PCM

\section{A. Energy investigation of the solar still with PCM}

The goal of energy analysis is to create calculations that can be used to investigate the temperature of multiple elements of solar stills, including the condenser transparent shield, salt water, absorption plate, and PCM layer. The solar radiation that strikes the condenser's glass cover is performed through this one, while the rest is mirrored in the environment. A portion of the solar energy that penetrates the glass is soaked up by the glass, while the remainder reaches the surface of the salt water in the pool.Just a minor part of the energy is mirrored off the top of the water, with the rest passing through to the absorption plate.The absorbingplatter absorbs the huge amounts of energy and reflects the least amount of energy. The energy that is absorbed by the absorber is transmitted to the salt water and, if contain, the PCM layer at the absorber's bottom. PCM saves energy that otherwise would have been ended up losing at the solar still's bottom. However, as shown in Fig. 4, Heat transfer via floor insulation loses only a slight part of the energy.

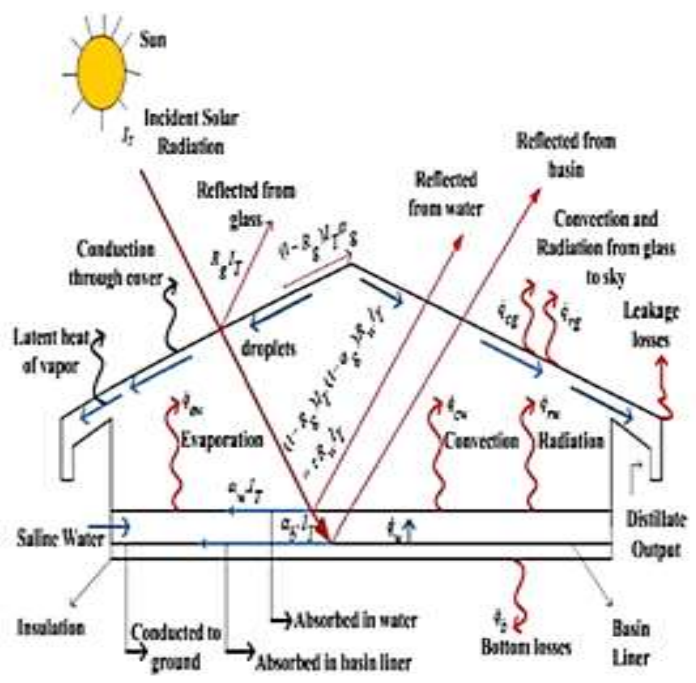

Fig. 4. Energy balance for solar still

The basic assumptions underpin the energy equilibrium equation:

a) The solar still does not produce any steam.

b) Minimal heat loss by the solar still's sidewalls. 
c) The condenser glass cover and the salt water are at the same heat.

d) In the PCM layer, there should be no conductivity.

e) Because the PCM is so thin, there is no temperature gradient all through it.

\section{SOLAR STILL ENERGY STORAGE FRAMEWORK}

Heat energy storage systems heat or cool the collection medium to store energy. The energy stored can also be used for warming, refrigeration, or electricity generation. Thermochemical energy storage systems are most common types of energy storage systems used within solar stills. The comprehensive description of energy storage systems for solar systems is shown in Figure 5 [11]. For implementations including a solar still, thermal energy storage is favoured over chemical energy storage for financial purposes [12]. Heat energy storage in solar systems is done in a sensitive or hidden manner. Heat is stored in heat-sensitive materials by ranging the temperature of the material [13].

Basalt stones [14], black stones [15], and steel wool fibres [16] have all been usedbyspecific researchers have proposed it as a viable heat storage system in solar stills. When a substance undergoes a phase transformation,latent heat storage materials, on the other hand, soak up and radiate heat. The sensible storage system is bigger than the traditional heat storage system and will continue to grow in size.PCM is a type of heat storage system that can store 5 to 14 times increased heat than traditional thermal energy storage systems, making it ideal for solar distillation. The temperature is rising during in the charging cycle, The chemical bonds inside the PCM are broken, and the stage of the material shifts from solid to liquid. The temperature remains constant until the melting procedure is completed. Whenever the heat around a fluid PCM drops, the PCM reinforces and releases the stored heat generated [17].

While the thermal output is low, a PCM with a lower fusing temperature is selected to help reduce the working temperature. If the heating power is relatively high, PCM with a high melting point is preferred to obtain a longer heating rate [18, 19].Fig. 6displays the sorting of PCM [20].

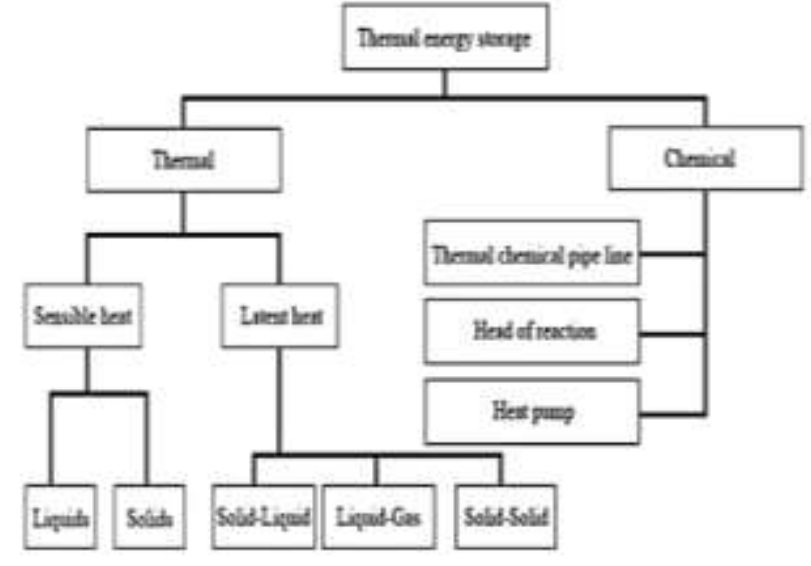

Fig. 5. Heat energy storage system for solar still implementations

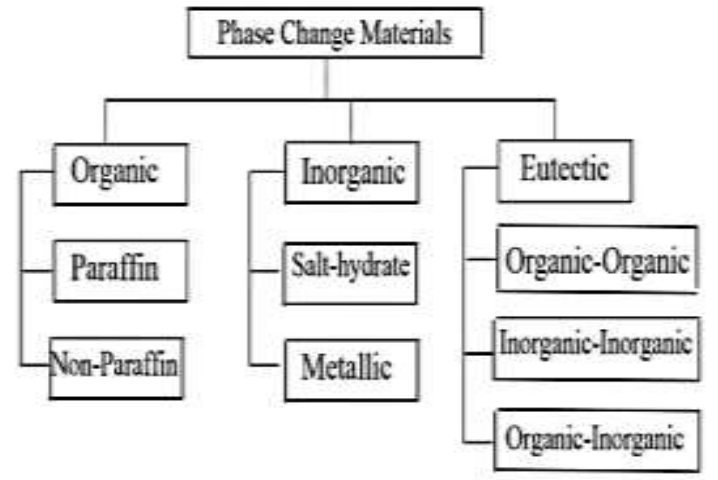

Fig. 6. Categorization of PCM

\section{CONCLUSION}

PCM are substances that store the energy as latent heat by adjusting phase at specific melting and solidification temperature range. Such substances have an elevated heat of fusion, meaning they can store and release a lot of heat throughout liquefaction and crystallisation. We summarized the findings as:

1. Using PCM, daytime productivity is reduced slightly, while nighttime productivity and overall productivity are risen.

2. When compared to conventional solar stills, the a hybrid solar distillation system's price per litreusing PCM is slightly higher.

3. The use of PCM in the solar stills improves the system's efficiency.

According to a wide range of research papers, the amount of water that has collected on the surface comparison to the number of water produced in the experimental set - up although during process. They were on the same page. The 
speed of clean water manufacturing did not vary significantly as a result about using innovative heat transfer coefficients in Computational fluid dynamics that were assessed for experimental evidence, but it did have an impact on water heating results and reduced error compared to earlier numerical simulations. CFD simulation results demonstrate that $\mathrm{CFD}$ is an effective instrument for solar still architecture, parameter assessment, and problem solving.

\section{REFERENCES}

[1] A. Ahsan, M. Imteaz, U. A. Thomas, M. Azmi, A. Rahman, and N. N Nik Daud, "Parameters affecting the performance of a low cost solar still," Appl. Energy, vol. 114, pp. 924-930, 2014, doi: 10.1016/j.apenergy.2013.08.066.

[2] C.Gnanavel, R.Saravanan, M.Chandrasekaran "CFD analysis of solar still with PCM", IEEE Materials Today: Proceedings, Volume 37, Part 2, 2021, Pages 694-700.

[3] PratibhaKuraria, Tanya Saxena, Amrit Kumar Dhamneya "Solar Still Performance Enhancement using PCM \& Nanoparticles", International Research Journal of Engineering and Technology (IRJET), Volume: 07 Issue: 08 | Aug 2020.

[4] Farhan Lafta Rashid, Abbas SahiShareef "Performance Enhancement of a New Passive Solar Still Design for Water Desalination", IEEE Journal of Mechanical Engineering Research and Developments ISSN: 1024-1752, Vol. 43, No. 3, pp. 75-85 Published Year 2020.

[5] Swellam W. Sharshir, Ammar H. Elsheikh, Elbager M.A. Edreis "Improving the solar still performance by using thermal energy storage materials: A review of recent developments", Desalination and Water Treatment, 165 (2019) 1-15 October

[6] C Uma Maheswari and R Meenakshi Reddy "CFD Analysis of different types of single basin solar stills", IOP Conf. Series: Materials Science and Engineering 330 (2018) 012097.

[7] Ali Saeed M M, Mohsen MS, Hachim D M, Hameed H G (2019) "numerical simulation for single slope solar still performance with optimal amount of nano PCM". Journal of advanced Res in Fluid Mech and Thermal Sci, 63, 302-316.

[8] Elashmawy, M. (2017). "An experimental investigation of a parabolic concentrator solar tracking system integrated with a tubular solar still". Desalination, 411, 1-8.

[9] Kabeel, A. E., Sharshir, S. W., Abdelaziz, G. B., Halim, M. A., \&Swidan, A. (2019). "Improving performance of tubular solar still by controlling the water depth and cover cooling". Journal of cleaner production, 233, 848-856.

[10] Hussein Ali Jabar, "Experimental and theoretical study of performance of tubular solar still in iraq," no. June, 2016.

[11] I. Sarbu, C. Sebarchievici, A comprehensive review of thermal energy storage, Sustain. 10 (2018), https://doi.org/10.3390/su10010191.

[12] N. Khan, S. Dilshad, R. Khalid, A.R. Kalair, N. Abas, Review of energy storage and transportation of energy, Energy Storage 1 (2019) 1-49, https://doi.org/10.1002/ est2.49.

[13] L.G. Socaciu, Thermal energy storage with phase change material, leonardo electron, J. Pract. Technol. 11 (2012) 75-98.

[14] A.F. Mohamed, A.A. Hegazi, G.I. Sultan, E.M.S. El-Said, Augmented heat and mass transfer effect on performance of a solar still using porous absorber: experimental investigation and exergetic analysis, Appl. Therm.
Eng.
150
(2019)
1206-1215,

[15] M.R. Kumar, M. Sridhar, S.M. Kumar, C.V. Vasanth, Experimental investigation of solar water desalination with phase change material and tio 2, Imp. J. Interdiscip. Res. (2017) 1128-1134 doi:ISSN: 2454-1362.

[16] A.R.A. Elbar, M.S. Yousef, H. Hassan, Energy, exergy, exergoeconomic and enviroeconomic (4E) evaluation of a new integration of solar still with photovoltaic panel, J. Clean. Prod. 233 (2019) 665-680, https://doi.org/10.1016/j.jclepro. 2019.06.111.

[17] B. Kanimozhi, K. Harish, B.S. Tarun, P.S. Sainath Reddy, P.S. Sujeeth, Charging and discharging processes of thermal energy storage system using phase change materials, IOP Conf. Ser. Mater. Sci. Eng. 197 (2017), https://doi.org/10.1088/ 1757-899X/197/1/012040.

[18] J. Hu, T. Guo, Y. Zhu, R. Hu, X. Luo, T. Cheng, Effect of melting temperature and amount of the phase change material (PCM) on thermal performance of hybrid heat sinks, Proc. Electron. Packag. Technol. Conf. EPTC. (2014) 48-52, https:// doi.org/10.1109/ICEPT.2014.6922584.

[19] Z. Andrassy, Z. Szanthó, Thermal behaviour of materials in interrupted phase change, J. Therm. Anal. Calorim. 138 (2019) 3915-3924, https://doi.org/10. 1007/s10973-019-08541-w.

[20] A. Shukla, K. Kant, A. Sharma, Solar still with latent heat energy storage: a review, Innov. Food Sci. Emerg. Technol. 41 (2017) 34-46, https://doi.org/10.1016/j. ifset.2017.01.004 